\title{
Çevre Koruma Amaçlı Tarımsal Eğitimlerin Chiftçi Davranışlarına Etkisi: Samsun İli Bafra İlçesi Örneği
}

\author{
Gamze AYDIN ERYILMAZ ${ }^{\text {* }}$, Osman KILIÇ ${ }^{2}$ \\ ${ }^{1}$ Ondokuz Mayls Üniversitesi, Samsun Meslek Yüksekokulu, Park ve Bahçe Bitkileri Bölümü, Samsun, TÜRKIYYE \\ ${ }^{2}$ Ondokuz Mayıs Üniversitesi, Ziraat Fakültesi, Tartm Ekonomisi Bölümü, Samsun, TÜRKIYYE
}

\begin{tabular}{ll}
\hline \multicolumn{1}{c}{ Geliş Tarihi/Received: 19.09 .2019} & Kabul Tarihi/Accepted: 11.11 .2019 \\
\hline ORCID ID (Yazar sırasma göre / by author order) \\
\hline (D) orcid.org/0000-0002-4440-8687 (Dorcid.org/0000-0002-0129-4034 \\
*Sorumlu Yazar/Corresponding Author: gamzeaydin@omu.edu.tr
\end{tabular}

Öz: Bu araștırmanın amacı, çevre koruma amaçlı tarımsal eğitimlerin çiftçi davranışlarına etkisini ortaya koymaktır. Araştırmanın verileri, Samsun ili Bafra ilçesinde çevre koruma amaçlı tarımsal eğitimlere katılan 56 çiftçiyle yapılan anketlerden elde edilmiştir. Çiftçiler çevre koruma amaçlı tarımsal eğitimlerin dışında; hayvancılık (\% 10.71), tıbbi ve aromatik bitki yetiştiriciliği (\% 8.93), meyvecilik (\% 5.36), seracılık (\% 3.57) ve arıcılık (\% 3.57) eğitimlerine de katılmıșlardır. Çiftçilerin \% 57.14'ü çevre koruma amaçlı tarım teknikleriyle ilgili eğitimleri faydalı ve çok faydalı bulduklarını ifade etmişlerdir. Çiftçiler, en fazla hastalık ve zararlılarla mücadele konusunda eğitim almak istediklerini belirtirken, bunu sırasıyla çeltik yetiştiriciliği ve gübrelemeyle ilgili eğitimler izlemektedir. Çiftçilerin çevre koruma amaçlı tarımsal eğitimin sonunda gösterdikleri en önemli davranış değişimi, gübre ve tarım ilaçlarının gıda ürünlerine bulaşmayacak şekilde muhafaza edilmesi olmuştur. Tarımsal eğitimden beklenen faydanın sağlanması, çiftçilerin elde ettikleri bilgileri işletmelerinde uygulamalarına bağlıdır. Bunun için, çevre koruma amaçlı tarımsal uygulamaların işletme kârını artırıcı özelikte olması gerekir. Araştırma sonuçları, çiftçilerin çevre korumayla ilgili eğitimlere katılma konusunda istekli olduklarını ve eğitimlerden elde ettikleri bilgileri büyük ölçüde işletmelerinde uyguladıklarını göstermektedir.

Anahtar Kelimeler: Çevre koruma, tarımsal eğitim, çiftçi davranışları, gübre, tarım ilacı

\section{The Effect of Agricultural Trainings for Environmental Protection on Farmer Behavior: The Case of Bafra District of Samsun}

\begin{abstract}
The aim of this study is to determine the effects of the agricultural trainings for environmental protection on farmer behavior. The data of the study were obtained from the surveys conducted with 56 farmers who participated in agricultural trainings for environmental protection in Bafra district of Samsun. In addition to agricultural training for environmental protection; farmers participated in training for animal husbandry (10.71\%), medicinal and aromatic plant cultivation $(8.93 \%)$, fruit production $(5.36 \%)$, greenhouse cultivation $(3.57 \%)$ and beekeeping $(3.57 \%)$. Of the farmers, $57.14 \%$ stated that they found the training about agricultural techniques for environmental protection useful and very useful. Farmers stated that they would like to receive training on pests and diseases control, followed by paddy cultivation and fertilization, respectively. The most important behavioral change that the farmers showed at the end of the agricultural training for environmental protection was the preservation of fertilizers and pesticides so as not to contaminate food products. The benefits expected from agricultural training depends on the application of the information obtained by farmers in their enterprises. For this purpose, agricultural practices for environmental protection should be capable of increasing operational profit. The results of the research show that farmers are willing to participate in environmental protection trainings and they apply the information obtained from the trainings to a large extent in their enterprises.
\end{abstract}

Keywords: Environmental protection, agricultural training, farmer behaviors, fertilizer, pesticide 


\section{Giriş}

Tarım ürünlerinde artan talebi karşılamak ve daha fazla gelir elde etmek amaciyla yapılan yoğun girdili üretime, gelecek nesilleri dikkate almayan duyarsız bir yaklaşımla uzun yıllar devam edilmiştir. Tarımda kontrolsüz girdi uygulamaları, çiftçileri gübre ve tarım ilacı kullanımına bağımlı kılarken, aynı zamanda bunları üreten ve ticaretini yapanları da çevre sorunlarına yol açan bir sektör haline getirmiştir. Doğanın dış müdahalelere karşı koyabilme ve kendini yenileyebilme kapasitesinin sınırlı olması, çevre ve doğal kaynakların korunmasına karşı özellikle eğitimli insanlarda büyük bir duyarlılık oluşturmuştur. Çevre sorunlarına yönelik yerel ve küresel düzeyde önlemlerin alınmasına ve toplumsal farkındalığın artırılmasına, uluslararası toplantı ve konferansların öncülük ettiği bir gerçektir. Özellikle 1972 Stockholm Konferansı'yla başlayan çalışmalar, ekonomik ve teknolojik önlemlerle birlikte çevre eğitiminin önemini ön plana çıkarmıştır (Şama, 2003). Uluslararası boyuttaki bu konferans, çevre sorunlarının kavranması bakımından bir dönüm noktası olmuştur. Birleşmiş Milletler tarafından 1992'de düzenlenen Rio Konferansı'nda, çevre sorunlarına yönelik önlemlerin alınmasında tüm bireylerin ortak sorumluluk almaları gerektiği vurgulanmıştır (Ertan, 1998). Toplumda çevre sorunlarına karşı artan duyarlılık, ilgili bakanlıklar ve sivil toplum örgütlerinin dâhil olduğu önemli sayıda kuruluşu harekete geçirdiği gibi, sürdürülebilir tarımla ilgili akademik çalışmalara da hız kazandırmıştır.

Tarımda sürdürülebilirliğin sağlanmasına yönelik önlemler, ülkelerin gelişmişlik düzeylerine göre farklılık göstermektedir. Gelişmekte olan ülkelerde sürdürülebilir tarım, g1da güvenliği ve yoksullukla mücadelenin önemli bir unsuru iken (Adenle ve ark., 2012), gelişmiş ülkelerde daha çok tarımda çevre kalitesi ve kaynakların kullanılabilirliği, insan sağlığı üzerindeki olumsuz etkileri, küçük işletmelerden kaynaklanan zorluklar ile kırsal alanda çölleşme gibi konuları ifade etmektedir (Marsh, 1997; Gafsi ve ark., 2006). Sürdürülebilir tarımın ekonomik ve sosyal bileşenlerinin yanı sıra; enerji etkinliği, toprak ve su kalitesi, yaban hayatının korunması, gıda ve yem güvenliği ile işletme güvenliğini kapsayan çevresel boyutu da vardır (Eryılmaz ve ark., 2019). Tarımda sürdürülebilirlik; teknik açıdan üretimde sürekliliğin sağlanması, ekonomik açıdan yeterli gelirin elde edilmesi, sosyal açıdan ise sosyal değişime ve gelişime açık bir kırsal yaşam ortamının sağlanması anlamına gelmektedir (Tatlidil ve ark., 2009).
Türkiye; uygun iklim koşulları, verimli toprak yapısı, su potansiyeli ve ürün çeşitliliğinin fazla olması bakımından tarım için elverişli bir yapıya sahiptir. Ancak yoğun girdili tarımsal faaliyetler nedeniyle bir taraftan toprak giderek bozulmakta, diğer taraftan kimyasal kalıntılardan dolayı su kaynakları ciddi zarar görmektedir. Bu durum tarımsal üretimin yoğun olduğu bölgelerde daha fazla ortaya çıkmaktadır. Araştırma alanı olan Samsun ili Bafra ilçesi, son yıllarda tarımsal faaliyetlerden kaynaklanan çevre sorunlarının gözlemlendiği tarım merkezlerinden biridir. Çevre sorunlarının en aza indirilmesini hedefleyen çalışmaların başarılı olması, küresel ölçekte olduğu kadar bireysel olarak da bilinçli hareket edilmesi ve sorumlulukların yerine getirilmesine bağlidır. Çevrenin korunmasını hedefleyen tarımsal uygulama ve programların yaygınlaşması, sürdürülebilir tarımın sağlanması için gerekli olmakla birlikte çiftçilere yönelik tarımsal eğitimler de önem kazanmaktadır. Tarımsal faaliyetlerini ağırlıklı olarak eski alışkanlıklarıyla yürüten çiftçilerin çevre konusundaki duyarlılıklarının, çevrenin korunmasına yönelik eğitimler sayesinde artması beklenmektedir. Bu araştırmanın amacı, Bafra ilçesinde çevre koruma amaçlı eğitimlerin çiftçi davranışlarına etkisini ortaya koymaktır. Araştırma sonuçları sayesinde, çiftçilerin tarımsal eğitimlere olan ilgi ve beklentilerinin tespit edilmesinin yanı sıra, eğitimlerden sağlanan faydanın da test edilmesi mümkün olacaktır. Ayrıca araştırma sonuçlarının, çevre koruma amaçlı eğitimlerin teknik ve ekonomik açıdan faydalı olmasını sağlayan tedbirlerin alınmasına ve buna göre gerekli düzenlenmelerin yapılmasına katkı sağlaması beklenmektedir.

\section{Materyal ve Yöntem}

Araştırmanın materyalini, Samsun ili Bafra ilçesinde çevre koruma amaçlı tarımsal eğitime katılan çiftçilerden anket yoluyla elde edilen veriler oluşturmaktadır. Araştırmada, örnekleme birimi olarak işletme arazisi büyüklüğü esas alınmıştır. Anket sayısının belirlenmesinde, tabakalı tesadüfi örnekleme yöntemi kullanılmıştır (Yamane, 1967). Buna göre, anket yapılan işletme sayısı 56 olarak tespit edilmiştir.

Anketlerde, aile reisi konumundaki çiftçiler ile işletmelerin sosyo-ekonomik özelliklerine yönelik sorular sorulmuştur (yaş, eğitim, nüfus, tarımsal deneyim, işletmede çalışılan süre, arazi ve mülkiyet durumu, arazi tasarrufu, büyükbaş ve küçükbaş hayvan sayısı). Ayrıca anketlerde tarımsal eğitimler, bilgi kaynakları, eğitimlerden faydalanma durumu ve eğitim alınması istenen konularla ilgili sorular da yer almaktadır. 
Araştırmada, tarımsal eğitimlerle ilgili çiftçilerin görüşleri ile çevre koruma amaçlı tarımsal eğitimlerin çiftçi davranışlarına etkisinin belirlenmesinde, likert ölçeğiyle hazırlanan sorular kullanılmıştır. Çiftçilerin sorulara kesinlikle katılmıyorum/hiçbir zaman (1), katılmıyorum/ nadiren (2), kararsızım/ara sira (3), katıliyorum/ genellikle (4), kesinlikle katılıyorum/her zaman (5) şeklinde verdikleri cevaplar yüzde olarak değerlendirilmiştir. Verilen cevapların öncelik sırası, ortalamadan hareketle hesaplanan değere göre belirlenmiştir.

\section{Bulgular ve Tartışma}

Anket yapılan çiftçilerin yaş ortalaması 54.64 yıl, eğitim gördükleri süre 6.4 yıl ve tarımsal deneyimleri ise 33.7 yıldır. Bitkisel üretimde bir yıldaki çalışma süresi, arazi büyüklüğü ve üretim desenine bağlı olarak 5-12 ay arasında değişmektedir. İşletme başına düşen aile nüfusu 5.17 kişiden oluşmaktadır. İşletme arazisi 85.98 dekar olup, bunun \% 69.7'i mülk, \% 29.53'ü ise kiralanan araziye aittir. İşletme arazisinin yarıdan fazlasında (\% 58.69) çeltik üretimi yapılmaktadır. İşletmelerde çeltik üretimini sırasılyla buğday+kışlık sebze (\% 12.43), buğday+silajlık misir (\% 8.73) ve buğday (\% 7.66) üretim faaliyetleri izlemektedir. İşletme başına düşen büyükbaş hayvan sayısı 2.7 baş, küçükbaş hayvan sayısı ise 0.85 baştır (Tablo 1).
İşletmelerde çevre koruma amaçlı tarımsal eğitimin dışında, diğer tarımsal eğitimlere katılan çiftçiler de bulunmaktadır. Çiftçiler, çevre koruma amaçlı tarımsal eğitimin dışında \% 10.71'le en fazla hayvancılık eğitimine katılmışlardır. Bunu sırasıyla; tıbbi ve aromatik bitki yetiştiriciliği (\% 8.93), meyve yetiştiriciliği (\% 5.36), seracıllk (\% 3.57) ve arıcılıkla (\% 3.57) ilgili eğitimler takip etmektedir. Çiftçilerin eğitimle ilgili bilgi kaynakları içinde \% 37.5'le Bafra İlçe Tarım ve Orman Müdürlüğü ilk sıradadır. Çiftçilerin diğer önemli bilgi kaynakları, \% 32.14'le üretici birlikleri ve \% 14.29'la tarım danışmanlarıdır. Çiftçilerin \% 57.14'ü katıldıkları eğitimleri faydalı ve çok faydalı bulurken, eğitimler için faydalı değil ve hiç faydalı değil diyenlerin oranı \% 25.00'tir. Çiftçilerin en fazla eğitim almak istedikleri konu, \% 30.36'yla hastalık ve zararlılarla mücadeledir. Çiftçilerin eğitim almak istedikleri diğer konular; çeltik yetiştiriciliği $\left(\begin{array}{ll}\% & 25.00\end{array}\right)$, gübreleme (\% 25.00), pazarlama (\% 23.21), hayvancıllk (\% 16.07) ve sulamadır (\% 5.36) (Tablo 2).

Çiftçiler, tarımsal eğitimlerden en fazla ürünlerin daha uygun şartlarda pazarlanması konusunda izlenmesi gereken yolları öğrendiklerini belirtmişlerdir (4.20). Bunu eğitimlerden sağladıkları bilgileri işletmesinde uygulayanlar takip etmektedir (4.15). Tarımsal eğitimlerden sonra toprak analizi yaptırmaya başlayan çiftçilerin oran $1 \% 80.36$ iken, diğer çiftçiler gübrelemeyi aile

Tablo 1. Sosyo-ekonomik özellikler

\begin{tabular}{lcccc}
\hline & Ortalama & Minimum & Maksimum & Standart sapma \\
\hline Çiftçiye ait özellikler & & & & \\
\hline Yaş (yıl) & 54.64 & 33 & 80 & 12.11 \\
Eğitim durumu (yıl) & 6.04 & 1 & 16 & 2.88 \\
Tarımsal deneyim (yıl) & 33.70 & 7 & 58 & 13.72 \\
İşletmede çalışılan süre (ay yıl'-1) & 11.47 & 5 & 12 & 1.71 \\
\hline İşletmeye ait özellikler & & & & \\
\hline Aile nüfusu (kişi) & 5.17 & 1 & 11 & 2.09 \\
İşletme arazisi (da) & 85.98 & 10 & 380 & 65.85 \\
Mülk & 59.93 & 5 & 250 & 48.45 \\
Kiralanan & 25.39 & 5 & 200 & 34.37 \\
Ortağa tutulan & 2.12 & 17 & 50 & 9.48 \\
Kiraya ve ortağa verilen & 1.46 & 20 & 36 & 6.29 \\
Arazi kullanımı (da) & & & & \\
Buğday & 6.59 & 2.50 & 30 & 7.67 \\
Fiğ & 3.83 & 1 & 9 & 4.46 \\
Çeltik & 50.46 & 10 & 90 & 58.69 \\
Buğday+silajlık mısır (II. ürün) & 7.51 & 6 & 48 & 8.74 \\
Buğday+mısır (II. ürün) & 3.04 & 4 & 18 & 3.54 \\
Buğday+kışlık sebze (II. ürün) & 10.69 & 3 & 58 & 12.43 \\
Biber (salçalık) & 2.30 & 3 & 15 & 2.67 \\
Yazlık sebze+kışlık sebze (II. ürün) & 1.55 & 1 & 12 & 1.80 \\
Büyükbaş hayvan sayısı (baş) & 2.70 & 1 & 15 & 2.82 \\
Küçükbaş hayvan sayısı (baş) & 0.85 & 1 & 5 & 1.32 \\
\hline
\end{tabular}


Tablo 2. Tarımsal eğitimler, bilgi kaynakları ve eğitimlerden faydalanma durumu

\begin{tabular}{lcc}
\hline & Sayı & $(\%)$ \\
\hline Tarımsal eğitimler* & & \\
\hline Çevre koruma amaçlı tarımsal eğitim & 56 & 100.00 \\
Diğer tarımsal eğitimler & & \\
Hayvancılık & 6 & 10.71 \\
Tibbi ve aromatik bitki yetiştiriciliği & 5 & 8.93 \\
Meyvecilik & 3 & 5.36 \\
Seracılık & 2 & 3.57 \\
Arıcılık & 2 & 3.57 \\
\hline Eğitimlerle ilgili bilgi kaynakları & & \\
\hline İlçe Tarım ve Orman Müdürlüğ̈ & 21 & 37.50 \\
Üretici birliği & 18 & 32.14 \\
Tarım danışmanı & 8 & 14.29 \\
Muhtar & 6 & 10.71 \\
Akraba & 3 & 5.36 \\
\hline Toplam & 56 & 100.00 \\
\hline Ĕ̆itimlerden faydalanma durumu & & \\
\hline Çok faydalı & 13 & 23.21 \\
Faydalı & 19 & 33.93 \\
Kararsızım & 10 & 17.86 \\
Faydalı değil & 8 & 14.29 \\
Hiç faydalı değil & 6 & 10.71 \\
\hline Toplam & 56 & 100.00 \\
\hline Eğitim alınması istenen konular* & & \\
\hline Hastalık ve zararlılarla mücadele & 17 & 30.36 \\
Çeltik yetiştiriciliği & 14 & 25.00 \\
Gübreleme & 14 & 25.00 \\
Pazarlama & 13 & 23.21 \\
Hayvancılık & 9 & 16.07 \\
Sulama & 3 & 5.36 \\
\hline *: Birden fazla seçenek isaretlenmistir. & &
\end{tabular}

büyüklerinden öğrendikleri şekliyle ya da geçmiş tecrübelerine göre yaptıklarını belirtmişlerdir. Tarımsal eğitimlerin düzenli yapıldığı görüşüne katılmıyorum diyen çiftçilerin oranı \% 37.5 iken, kesinlikle katılmıyorum diyenlerin oranı
\% 19.64'tür. Kadınların tarımsal eğitime katılma kararında etkilerinin oldukça zayıf olduğu görülmektedir. Öyle ki tarımsal eğitimlerle ilgili kararlarda, kadınların etkili olduğuna kesinlikle katılmıyorum ve katılmıyorum diyenlerin oranı \% 64.29'dur (Tablo 3). Samsun ili Çarşamba ilçesinde yapılan bir araştırmada, kadınlar yetiştirdikleri ürünlerle ilgili tarımsal eğitime katılma konusunda istekli olmalarına rağmen, kadınların tarımla ilgili herhangi bir eğitim almadıkları tespit edilmiştir. Aynı araştırmaya göre, kadınların tarımsal bilgiye erişim kaynakları büyük ölçüde eş ya da oğullarıdır (Alkan, 2015).

Araştırma sonuçları, çevre koruma amaçlı tarımsal eğitimin sonrasında gösterilen en önemli davranış değişiminin, gübre ve tarım ilaçlarının gıda ürünlerine bulaşmayacak şekilde muhafaza edilmesi (4.75) olduğunu göstermektedir. Çevre koruma amaçlı eğitimden sonra, ürünün yetişme dönemi boyunca her zaman uygun miktarlarda gübre uyguladığını ifade eden çiftçilerin oranı $\%$ 47.62'dir. Çevre korumaya yönelik eğitimin sonrasında atık depolama alanını genellikle kullanırım diyen çiftçilerin oranı \% 33.33, her zaman kullanırım diyenlerin oranı ise \% 42.86 olarak belirlenmiştir. Çiftçilerin \% 9.52'si gübre ve tarım ilacı kutularını atık depolama alanlarına hiçbir zaman atmadıklarını belirtmişlerdir (Tablo 4). Araştırma alanında daha önce yapılan bir araştırmaya göre, iyi tarım uygulamalarına yönelik eğitimlerin sonunda gübre ve tarım ilaçlarını doğru şekilde uygulamaya başlayan çiftçilerin oranı \% 47.9'dur (Türkten ve ark., 2014). Giresun ilinde yapılan bir araştırmada, findık işletmelerinin \% 66'sının ilaçlamadan sonra ambalajları yakarak imha ettikleri, ayrıca ambalajları toprağa gömen $(\% 8)$ ve çevreye atan (\% 2) çiftçilerin de bulunduğu tespit edilmiştir (Kılıç ve ark., 2018).

Tablo 3. Tarımsal eğitimlerle ilgili çiftçi görüşleri (\%)

\begin{tabular}{|c|c|c|c|c|c|c|}
\hline & 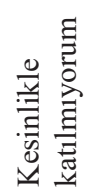 & 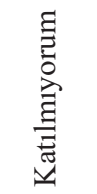 & 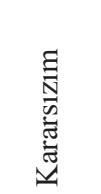 & 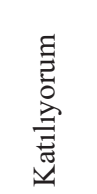 & 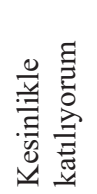 & 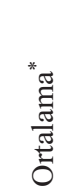 \\
\hline $\begin{array}{l}\text { Eğitimler sonrası ürünlerin pazarlanması konusunda } \\
\text { izlemem gereken yolları öğrendim }\end{array}$ & - & 14.29 & 28.57 & 51.79 & 5.36 & 4.20 \\
\hline Ĕgitimlerden sağladığım bilgileri uyguladım & - & 8.93 & 5.36 & 57.14 & 28.57 & 4.15 \\
\hline Eğitimler sonrası toprak analizi yaptırmaya başladım & - & 19.64 & - & 46.43 & 33.93 & 4.05 \\
\hline Eğitimler sonrası alet-makine sayısını artırdım & - & 14.29 & - & 66.07 & 19.64 & 4.05 \\
\hline Eğitimlere katılmaya istekliyim & - & 8.93 & 19.64 & 48.21 & 23.21 & 3.95 \\
\hline Eğitimler sonrası ürünlerin veriminde artış oldu & - & 10.71 & 28.57 & 37.50 & 23.21 & 3.85 \\
\hline Eğitimi veren kişiler tarımsal konularda bilgilidir & 8.93 & 14.29 & 14.29 & 42.86 & 19.64 & 3.60 \\
\hline Eğitimler düzenli olarak yapılmaktadır & 19.64 & 37.50 & 14.29 & 19.64 & 8.93 & 2.70 \\
\hline Kadınlar tarımsal eğitimlerle ilgili kararlarda etkilidir & 37.50 & 26.79 & 8.93 & 10.71 & 16.07 & 2.09 \\
\hline
\end{tabular}


Tablo 4. Çevre koruma amaçlı tarımsal eğitim sonrası çiftçi davranışları (\%)

\begin{tabular}{|c|c|c|c|c|c|c|}
\hline & 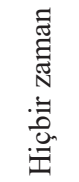 & 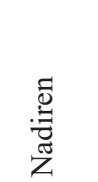 & $\begin{array}{l}\frac{\pi}{G} \\
\frac{\pi}{2} \\
\frac{\pi}{4}\end{array}$ & 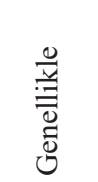 & 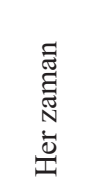 & 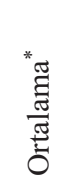 \\
\hline $\begin{array}{l}\text { Gübre ve tarım ilacını gıda ürünlerine bulaşmayacak şekilde } \\
\text { muhafaza ederim }\end{array}$ & - & - & 4.76 & 23.81 & 71.43 & 4.75 \\
\hline $\begin{array}{l}\text { Bitki hastalık ve zararlıların yoğunluğunu tespit ederek } \\
\text { gerektiği zamanda ve uygun miktarda tarım ilacı kullanırım }\end{array}$ & 4.76 & 14.29 & 19.05 & 28.57 & 33.33 & 4.70 \\
\hline Gübreyi yetiştirme dönemi boyunca uygun miktarda uygularım & - & - & 4.76 & 47.62 & 47.62 & 4.50 \\
\hline $\begin{array}{l}\text { Tarımsal atıkların birbirleriyle reaksiyona girmesini önleyecek } \\
\text { şekilde atılmasına dikkat ederim }\end{array}$ & - & - & 19.05 & 38.10 & 42.86 & 4.45 \\
\hline Gübre ve tarım ilacı kutularını atık depolama alanlarına atarım & 9.52 & - & 14.29 & 33.33 & 42.86 & 4.35 \\
\hline $\begin{array}{l}\text { Hastalık ve zararlılarla mücadelede tarım danışmanlarından } \\
\text { yardım alıım }\end{array}$ & - & 4.76 & 23.81 & 19.05 & 52.38 & 4.30 \\
\hline $\begin{array}{l}\text { Gübre uygulanan alan ile su kaynakları arasında güvenli bir } \\
\text { mesafe olmasına dikkat ederim }\end{array}$ & - & 14.29 & - & 42.86 & 42.86 & 4.25 \\
\hline Tarım ilacı uygularken eldiven ve koruyucu kıyafet kullanırım & - & 14.29 & 4.76 & 42.86 & 38.10 & 4.15 \\
\hline $\begin{array}{l}\text { Toprak yüzeyi kurumuş, çatlamış ya da islak olduğunda gübre } \\
\text { uygulamam }\end{array}$ & 9.52 & 4.76 & 9.52 & 28.57 & 47.62 & 4.15 \\
\hline Münavebeye önem veririm & - & 9.52 & 9.52 & 52.38 & 28.57 & 4.10 \\
\hline Gübrelemede eldiven ve koruyucu kıyafet kullanırım & - & 9.52 & 14.29 & 42.86 & 33.33 & 4.10 \\
\hline İşletmeyle ilgili kayıt tutarım & 9.52 & 14.29 & 33.33 & 19.05 & 23.81 & 3.80 \\
\hline
\end{tabular}

Araştırma sonuçlarına göre, eğitimlerden sonra tarım ilacı uygulamalarında çiftçilerin \% 42.86's1 genellikle, \% 38.10'u her zaman eldiven ve koruyucu kıyafet kullandıklarını belirtmişlerdir. Eğitim sonrası, eldiven ve koruyucu kıyafetleri hiçbir zaman kullanmıyorum diyen çiftçiye rastlanmamıştır (Tablo 4). Adıyaman ilinde yapılan bir araştırmada, eğitim sonrası pestisit uygularken çiftçilerin eldiven ve koruyucu elbise kullanımında olumlu yönde değişmeler olduğu tespit edilmiştir. Aynı araştırmaya göre, eğitim sonrası eğitim öncesine göre her zaman eldiven kullananların oranı \% 47.5, koruyucu kıyafet kullananların oranı ise \% 30 artmıştır (Tunçdemir, 2016).

Araştırma sonuçları, eğitimlerin çiftçilere kayıt tutma alışkanlığı kazandırmasındaki etkisinin oldukça zayıf olduğunu göstermektedir. Eğitim sonrası, genellikle ve her zaman kayıt tutmaya başladığını belirten çiftçilerin oranı \% 42.86'dır (Tablo 4). Tekirdağ ilinde yapılan bir araştırmaya göre, önder çiftçi danışmanlık derneği üyelerinin \% 49.6'sı tarım danışmanı vasıtasıyla, işletmelerinde kayıt tutma alışkanlığ kazandıklarını ifade etmişlerdir (Arap, 2016).

\section{Sonuçlar}

Tarımda yapılan bilinçsiz uygulamalar nedeniyle, çevre ve doğal kaynaklara yönelik tehditler giderek artmaktadır. Tarımsal sürdürülebilirliğin tüm toplumu ilgilendiren ortak bir olgu olması, üretimden tüketime kadarki süreçte etkili tüm aktörlere önemli sorumluluklar yüklemektedir. Tarımsal kaynaklı çevre sorunlarının giderilmesinde, kanunlarla getirilecek yaptırımların etkili olacağı bir gerçektir. Ancak tarım işletmelerinin denetim altına alınmasının, çiftçilerde çevre bilincinin geliştirilmesinde yeterli olmayacağı göz ardı edilmemelidir. Bu nedenle çiftçiler başta olmak üzere, tüm toplumda çevre koruma bilincinin kazandırılması için eğitim çalışmalarına öncelikli olarak yer verilmelidir.

Araştırmada, çiftçilerin tarımsal eğitimlere katılma konusunda istekli oldukları ve aldıkları eğitimlerden edindikleri bilgileri işletmelerinde büyük ölçüde uyguladıkları anlaşılmaktadır. Eğitimlerin verilme sıklığıla ilgili olarak çiftçilerdeki genel kanı, köylerde tarımsal eğitimlerin düzenli olarak yapılmadığıdır. Eğitimlerin çiftçiler açısından daha etkili olması, eğitimlerin periyodik olarak tekrarlanmasına ve çiftçiler ile eğitim kurumları arasında kurulacak güçlü iletişime bağlıdır. Eğitimlerde görev alan teknik personelin, bölgedeki tarımsal konulara hâkim olması ve düzenli olarak bilgilerini yenilemeleri önemlidir. Eğitimcilerin iletişim konusundaki becerilerinin geliştirilmesiyle, çiftçilere daha kolay ve etkin bilgi transferi sağlanabilecektir. Böylece eğitimleri faydalı bulan çiftçilerin, diğer çiftçilere tavsiyeleriyle daha sonra yapılacak eğitim çalışmalarına olan ilgi ve katılım artacaktır. 
Çevre koruma amaçlı eğitimlerle sağlanan kazanımların devamlılığı için, eğitimlerden elde edilen bilgilerin işletmelerde uygulanabilir olması gerekir. Araştırma sonuçları, tarımsal eğitimlerin çiftçi davranışları açısından en önemli etkilerinin gübre ve tarım ilaçlarının uygun koşullarda muhafaza edilmesi, hastalı ve zararlilarla mücadele ile gübreleme konusunda olduğunu göstermektedir. Eğitimlerin üretim tekniklerinin uygulanması üzerindeki olumlu etkilerine rağmen, eğitim sonrasında özellikle gübre ve tarım ilacı uygulamalarında koruyucu önlemler alma, münavebe ve kayıt tutma konularında çiftçilerin eksiklileri devam etmektedir. Bu açıdan çiftçilerin sorunları doğru tespit edilerek, eğitimlerde öncelikli konular üzerinde daha fazla durulması önemlidir.

Çiftçilerin çevre dostu tarımsal teknikleri uygulamaları için alacakları eğitimlerde başarının koşulu, eğitim faaliyetlerinin öncelikle çiftçilerde bilgi değişimine, daha sonra da davranış değişimine yol açmasıdır. $\mathrm{Bu}$ yüzden çiftçilere çevre dostu tarımsal tekniklerin öğretilmesini amaçlayan programları yürütecek uzmanların, uygulamalı tarım ve yaygın eğitim teknikleri konularında yeterli donanıma sahip olmaları gerekir. Ayrıca uzmanlarca yapılacak düzenli ziyaretlerle işletmeler takip edilmeli, aksayan konular için gerekli önlemler zamanında alınmalıdır. Sürdürülebilir tarımın sağlanmasında, çiftçilerde çevre bilincinin geliştirilmesi ve bu bilincin çiftçi davranışlarına yansıması tek başına belirleyici olmamaktadır. Tarımsal üretimi gerçekleştiren çiftçiler başta olmak üzere, ulusal ve küresel düzeyde çevre bilincinin yaygınlaşması, gelecek nesillerin tarımsal kaynaklardan faydalanma hakkının korunması açısından önem arz etmektedir.

\section{Kaynaklar}

Adenle, A.A., Sowe, S.K., Parayil, G., Aginam, O., 2012. Analysis of open source biotechnology in developing countries: An emerging framework for sustainable agriculture. Technology in Society, 34(3): 256-269.

Alkan, H.I., 2015. Tarım sektöründe kadın emeği
(Çarşamba Ovası Gündoğdu ve Damlataş köylerinde fındık, çeltik ve sebze üretimi özelinde bir irdeleme). Doktora tezi, Gazi Üniversitesi Sosyal Bilimler Enstitüsü, Ankara.

Arap, S., 2016. Önder çiftçi danışmanlık derneğinin üyeleri ile olan ilişkilerinin analizi: Tekirdağ ili örneği. Yüksek lisans tezi, Namık Kemal Üniversitesi Fen Bilimleri Enstitüsü, Tekirdağ.

Ertan, K. A., 1998. Çevre etiği. Amme İdaresi Dergisi, 31(1): 125-139.

Eryılmaz, G.A., Kılıç, O., Boz, İ., 2019. Türkiye'de organik tarım ve iyi tarım uygulamalarının ekonomik, sosyal ve çevresel sürdürülebilirlik açısından değerlendirilmesi. Yüzüncü Yıl Üniversitesi Tarım Bilimleri Dergisi, 29(2): 352-361.

Gafsi, M., Legagneux, B., Nguyen, G., Robin, P., 2006. Towards sustainable farming systems: Effectiveness and deficiency of the French procedure of sustainable agriculture. Agricultural Systems, 90: 226-242.

K1lıç, B., Uzundumlu, A.S., Tozlu, G., 2018. Fındık üretiminde kimyasal ilaç kullanımının çevresel duyarlıl1k yönünden incelenmesi: Giresun ili örneği. Türk Tarım ve Doğa Bilimleri Dergisi, 5(4): 396-405.

Marsh, J.S., 1997. The policy approach to sustainable farming systems in the EU. Agriculture, Ecosystems and Environment, 64(2): 103-114.

Şama, E., 2003. Öğretmen adaylarının çevre sorunlarına yönelik tutumları. Gazi Üniversitesi Gazi Ĕgitim Fakültesi Dergisi, 23(2): 99-110.

Tatlidil, F.F., Boz, İ., Tatlidil, H., 2009. Farmers' perception of sustainable agriculture and its determinants: a case study in Kahramanmaras province of Turkey. Environment, Development and Sustainability, 11(6): 1091-1106.

Tunçdemir, A., 2016. Adıyaman il merkezinde çiftçilerin güvenli pestisit kullanımı ile ilgili bilgi, tutum, uygulamaları ve eğitimin etkisi. Doktora tezi, İnönü Üniversitesi Sağlık Bilimleri Enstitüsü, Malatya.

Türkten, H., Eryılmaz, G.A., Ceyhan, V., Kılıç, O., 2014. Bafra ilçesinde çevre amaçlı tarım arazilerin korunması programının değerlendirilmesi ve iyi tarım uygulamalarının etkilerinin sürdürülebilirliği. $X I$. Ulusal Tartm Ekonomisi Kongresi, Bildiriler Kitab1, 3-5 Eylül, Samsun, s. 3-9.

Yamane, T., 1967. Elemantary Sampling Theory. Printice Hall Inc. Englewood Cliffs, Nt. 